\title{
Population structure of the malaria vector Anopheles darlingi in Rondônia, Brazilian Amazon, based on mitochondrial DNA
}

\author{
Aline F Angêlla, Luis HS Gil*, Luis HP da Silva*, Paulo EM Ribolla/ ${ }^{+}$ \\ Departamento de Parasitologia, Instituto de Biociências, Universidade Estadual Paulista, Distrito de Rubião Jr. s/n , 18618-000 \\ Botucatu, SP, Brasil *Instituto de Pesquisa em Patologias Tropicais, Porto Velho, RO, Brasil
}

Anopheles darlingi is the most important Brazilian malaria vector, with a widespread distribution in the Amazon forest. Effective strategies for vector control could be better developed through knowledge of its genetic structure and gene flow among populations, to assess the vector diversity and competence in transmitting Plasmodium. The aim of this study was to assess the genetic diversity of An. darlingi collected at four locations in Porto Velho, by sequencing a fragment of the ND4 mitochondrial gene. From 218 individual mosquitoes, we obtained 20 different haplotypes with a diversity index of 0.756, equivalent to that found in other neotropical anophelines. The analysis did not demonstrate significant population structure. However, haplotype diversity within some populations seems to be over-represented, suggesting the presence of sub-populations, but the presence of highly represented haplotypes complicates this analysis. There was no clear correlation among genetic and geographical distance and there were differences in relation to seasonality, which is important for malarial epidemiology.

Key words: malaria - Anopheles darlingi - mtDNA - ND4

Anopheles (Nyssorhynchus) darlingi is the main malaria vector in the Amazon Basin (Deane 1947, 1988). In addition to its role in the transmission of Plasmodium falciparum, this mosquito is also a vector of other species of Plasmodium (Klein et al. 1991). Its geographical distribution and density are intimately related to malaria; this mosquito is frequently found infected with the parasite, and sometimes by more than one type of Plasmodium (Tadei et al. 1998). Its extensive distribution ranges from Eastern Mexico to Northern Argentina (Forattini 2002).

Not only is An. darlingi morphologically undistinguished across its broad range, but its habits can vary with location. Studies in the state of Amapá demonstrated a significant increase in the density of An. darlingi at the end of the rainy season, and also a pronounced peak in nocturnal activity (Voorham 2002). In contrast, studies in Pará showed an earlier, pronounced hematophagic activity at dusk (Tadei et al. 1998). In a similar study in the Bolivian Amazon, activity occurred after dusk, between 19:00 and 21:00 h (Tadei et al. 1983). In Rondônia, occasionally this species shows very low after-dusk activity, and its annual density peaks vary depending on the proximity of large water bodies (Harris et al. 2006). In riverside communities, density peaks coincide with the end of the rainy season between April and May; but in some agricultural areas, the population increases only during the second half of the dry season (September and October) (Gil et al. 2003). This plasticity in hematophagic activity can result in an increase of the vector potential, and control

Financial support: FAPESP

${ }^{+}$Corresponding author: pribolla@ibb.unesp.br

Received 24 July 2007

Accepted 11 December 2007 strategies should be locally or regionally adapted according to the differences in its contact with humans.

Because of the inefficiency of the techniques such as morphological analysis, polytene chromosomes, biochemistry analysis (isoenzymes) used to identify the variations within species, molecular tools have been used to characterize different populations. The importance of studies done with mitochondrial DNA (mtDNA) genes is increasing, because of their exclusive properties. In the great majority of cases, the mitochondrial genome consists of a small, circular molecule with conserved genetic content (only 37 genes) and a simple genomic structure (maternal inheritance, absence of recombination, intergenic areas small or absent, and absence of introns, repetitive DNA, pseudogenes and transposable elements) (Moritiz et al. 1987). The molecule evolves about 5-10 times faster than the rate of nuclear genes (Brown 1985, Moritiz et al. 1987, Harrison 1989). These and other characteristics make it a good molecular marker for use in population studies. From the data on the mtDNA sequences, we can assess phylogenetic relationships among populations (Yamauchi et al. 2004).

The aim of this study was to analyze the genetic relationships within $A n$. darlingi populations in the vicinity of Porto Velho, and to understand the annual seasonal variability.

\section{MATERIALS AND METHODS}

Mosquito collection - Mosquitoes were collected at dusk (from 18:00 to 22:00 h) according to their highest density period (Gil et al. 2003 ) in April and October 2005, at four locations in Porto Velho, state of Rondônia: Portuchuelo (PT) (08 37' 45.6" S 63 49' 29.2" W), Bate-Estaca (BA) (08 48' 16.3" S 63 56' 26.4" W), Santo Antônio (SA) (08 48' 34.3" S 63 56' 34.3" W), and Vila Candelária (CA) $\left(08^{\circ} 47^{\prime} 17.8^{\prime \prime} \mathrm{S} 63^{\circ} 55^{\prime} 00.5^{\prime \prime}\right.$ W). Captures were performed acording to Gil et al. (2007) 
by trained volunteers supervised by the authors of this paper. Mosquitoes were identified as An. darlingi using a key for species of the subgenus Nyssorhynchus of America (Consoli \& Lourenço-de-Oliveira 1994). The identified specimens were immediately immersed in isopropanol for preservation and subsequent extraction of DNA. The collections were carried out in collaboration with researchers from Instituto de Pesquisa em Patologias Tropicais (IPEPATRO) and from the Tropical Medicine Research Center (CEPEM), both from Porto Velho. All four locations are along the Madeira River. PT and SA are the most distant from Porto Velho. BA and CA are located much closer to one another, in the outskirts of Porto Velho (Fig. 1).

Extraction of DNA - Using Chelex ${ }^{\circledR}$ Molecular Biology Grade Resin (Bio-Rad Laboratories, Hercules, USA), DNA was extracted from mosquitoes individually, following the manufacturer's recommendations.

Amplification reaction - Amplification reaction was conducted according to the protocol of GorrochoteguiEscalante et al. (2000), with modifications. Amplification was done in a final volume of $25 \mathrm{ml}$, using $1 \mathrm{ml}$ of the DNA sample, Tris- $\mathrm{HCl} 10 \mathrm{mM} \mathrm{pH} \mathrm{8.0,50} \mathrm{mM} \mathrm{KCl,}$ $1.5 \mathrm{mM} \mathrm{MgCl} 2,100 \mu \mathrm{M}$ dNTPs (PCR nucleotide mix, Invitrogen, Carlsbad, USA), $20 \mathrm{mM}$ of the specific oligonucleotides of the ND4 gene, ND4F (5'-TGATTGCCTAAGGCTCATGT-3') and ND4R (5' CTAGTCGTTCAT-3') (Invitrogen), and 1.0 U of Taq DNA polymerase (Biotools, Madrid, Spain). Amplification reactions were done in a Whatman Biometra (T Gradient) thermocycler with temperature cycles of: three cycles of $94^{\circ} \mathrm{C} / 2 \mathrm{~min}, 37^{\circ} \mathrm{C} / 2 \mathrm{~min}$, and $72^{\circ} \mathrm{C} / 1 \mathrm{~min}$, followed by 35 cycles of $94^{\circ} \mathrm{C} / 30 \mathrm{~s}, 50^{\circ} \mathrm{C} / 30 \mathrm{~s}$, and $72^{\circ} \mathrm{C} /$ $1 \mathrm{~min}$, with a final extension cycle of $72^{\circ} \mathrm{C} / 5 \mathrm{~min}$.

Purification of $m t D N A$ reaction - Polymerase chain reaction (PCR) products were submitted to electrophoresis in agarose gel according to Sambrook et al. (1989). Specific bands generated by the PCR reaction were purified with the Kit Concert Gel Extraction Systems (Gibco BRL, Invitrogen, Carlsbad, USA).

Data analysis - Products of the sequencing reaction were analyzed in an ABI Prism 377 sequencer. Chromatograms were manually corrected using Chromas 1.45

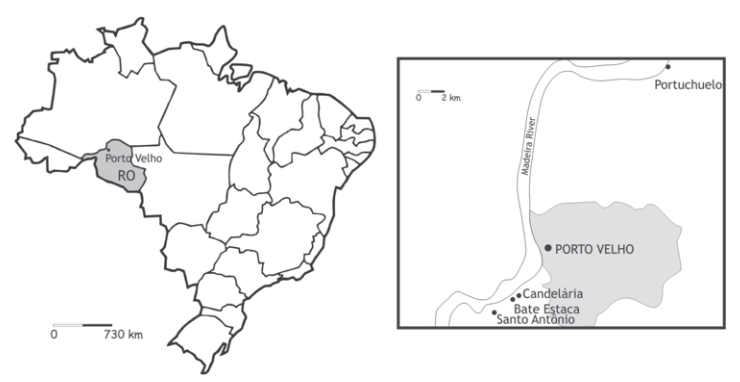

Fig. 1: localities where mosquitoes were collected. Left: Brazil, showing the state of Rondônia (RO) and its capital, Porto Velho; right: the area of Porto Velho, and location of the four collection sites along the Madeira River.
(Technelysium Pty. Ltd). The ND4 gene sequences (20 different haplotypes, GenBank accession numbers EU204621 to EU204640) were obtained from the PCR products and analyzed with the program MERGER (http:/ /bioweb.pasteur.fr/seqanal/alignment/intro-uk.html) in order to construct a consensus sequence from each mosquito sample. These sequences were aligned using Clustal W (Thompson et al. 1994) and misaligned nucleotides were manually adjusted. The program MEGA (Kumar et al. 2001) was used to perform phylogenetic and molecular analysis. Distance (Neighbor Joining, NJ) and parsimony methods were used to construct phylogenetic trees (Saito \& Nei 1987) using Kimura 2 parameters distance (Kimura 1980). A heuristic search was done to find all the most parsimonious trees. The robustness of NJ trees was tested by bootstrapping using 1,000 repetitions (Felsenstein 1985). Nucleotide sequences and haplotype frequencies were calculated using DnaSP version 3.5 (Rozas \& Rozas 1999). Genetic analysis of population differentiation, haplotype diversity index, Mantel correlation, and Chakraborty index were calculated with Arlequin 3.0 software (Excoffier et al. 2005). Mantel correlation was obtained by comparing the linearized $F_{S T}\left(F_{S T} / 1-F_{S T}\right)$ matrix with a $\log$ of the geographical distance matrix. Variations among, within, and between collections were partitioned by analysis of molecular variance (AMOVA) using the computer program Arlequin 3.0 ( Excoffier et al. 2005).

\section{RESULTS}

We analyzed a 249 bp ND4 gene fragment from 218 individuals from two collections. The fragment of the ND4 gene from 116 individuals collected in April 2005 was sequenced, revealing 13 haplotypes. Of the total number of polymorphic sites, five were singletons and 14 were parsimoniously informative. The populations showed a median number of nucleotide differences $\kappa=2.812$, with index of nucleotide diversity $\pi=0.01134$, and haplotype diversity $\mathrm{Hd}=0.731$. The gene fragments from 102 individuals collected in October 2005 were sequenced; in this case we detected 17 different (10 haplotypes were shared between April and October) haplotypes. Of the total number of polymorphic sites, nine were singletons, and 10 sites were parsimoniously informative. The populations showed a median number of nucleotide differences $(\kappa=3.065)$, with index of nucleotide diversity $\pi=0.01236$, and $\mathrm{Hd}=0.781$. Analysis of the four populations from both periods indicated no clear correlation between genetic distance and geographical distance $\left(r^{2}=0.048\right.$; Mantel $\left.p>0.1\right)$. Unlike the analyses of the first collection, where in April, CA population showed the highest nucleotide diversity (0.0137) and PT showed the lowest one (0.0097) in October, BA population showed the highest nucleotide diversity (0.0132), and the CA population the lowest diversity $(0.0111)$.

When we compared the mosquitoes collected in different months in 2005 (Fig. 2), we found that 10 of 20 haplotypes were present in both collections. In April, three exclusive haplotypes were present, and in October there were seven. All the exclusive haplotypes were present in very low frequencies; in most cases, only one individual harbored the haplotype. 
$F_{S T}$ pairwise population differentiation analysis was significant only between the two populations of PT $\left(F_{S T}=0.08 ; \mathrm{p}<0.05\right)$. Comparison of the mosquitoes collected in the two different periods (April and October) revealed no significant differentiation $\left(F_{S T}=0.005\right.$, $\mathrm{p}=0.2$ ). The AMOVA test showed no evidence of structure within populations. Most of the genetic differentiation $(99.86 \%)$ was explained when we made a pairwise comparison of individuals, independent of the collection point or the collection period. Also, when we compared the haplotype diversity of each population from the two periods (Fig. 3), it was possible to observe different patterns. There was a significant increase in the number of the haplotypes from what is expected from a normal distribution (Table). This may indicate the presence of sub-populations.

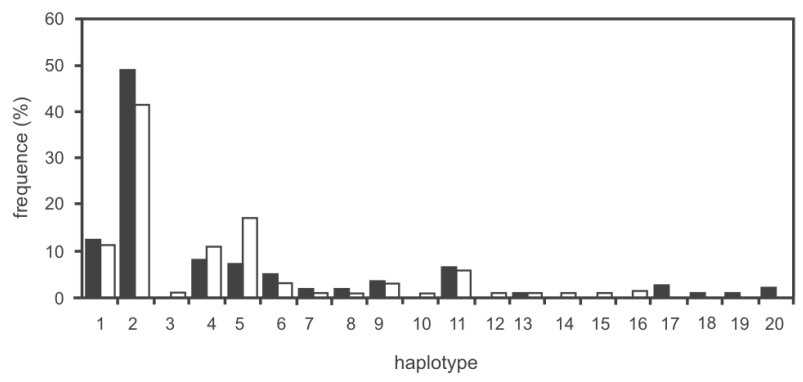

Fig. 2: haplotype frequencies of the ND4 gene from Anopheles darlingi mosquitoes collected in Rondônia. Black columns represent haplotypes from mosquitoes collected in April; white columns represent mosquitoes collected in October.
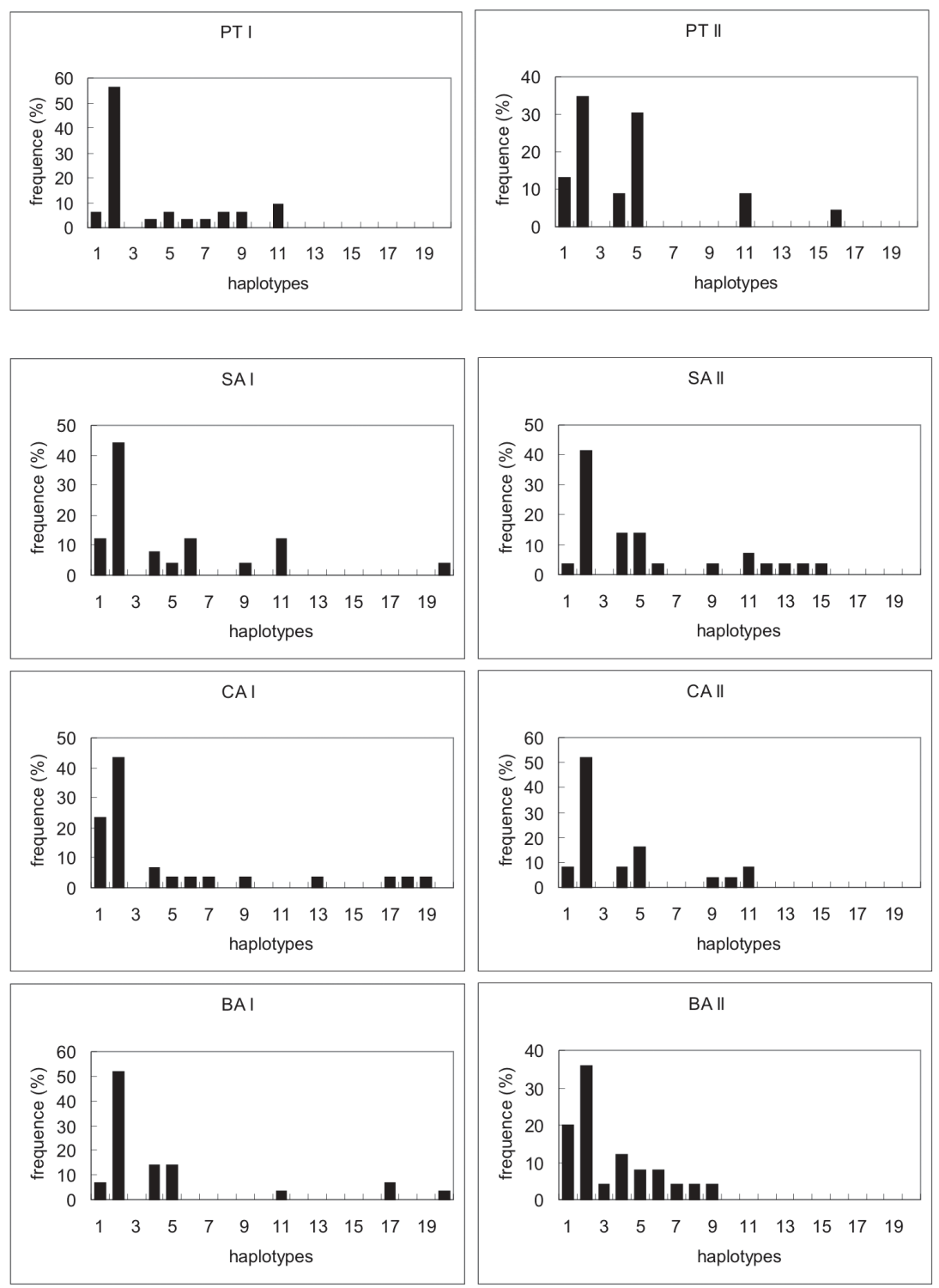

Fig. 3: haplotype distributions at different collection sites in April and October. BA: Bate Estaca; CA: Vila Candelária; PT: Portuchuelo; SA: Santo Antônio; I and II represents mosquitoes collected in April and October, respectively. 
TABLE

Genetic parameters of Anopheles darlingi populations from Rondônia

\begin{tabular}{lcccc}
\hline $\begin{array}{l}\text { Population/Month } \\
\text { of collection }\end{array}$ & $\mathrm{N}$ & $\mathrm{Pi}^{a}$ & $\begin{array}{c}\text { Number } \\
\text { of alleles }\end{array}$ & $\begin{array}{c}\text { Expected number } \\
\text { of alleles }\end{array}$ \\
\hline Portuchuelo/Apr & 32 & 2.40 & 9 & $5.4^{c}$ \\
Portuchuelo/Oct & 23 & 3.27 & 6 & 6.8 \\
Vila Candelária/Apr & 30 & 3.42 & 11 & $7.1^{c}$ \\
Vila Candelária/ Oct & 25 & 2.75 & 7 & 5.5 \\
Bate Estaca /Apr & 29 & 2.66 & 7 & 5.7 \\
Bate Estaca / Oct & 25 & 3.29 & 9 & 8.3 \\
Santo Antonio/Apr & 25 & 2.75 & 8 & 7.0 \\
Santo Antonio/Oct & 29 & 2.97 & 11 & 8.0
\end{tabular}

$a$ : heterozygosity; $b$ : expected number of alleles from Chakraborty (1990); $c: \mathrm{p}<0.05$

Phylogenetic analyses carried out by tree topology (Fig. 4) did not show clear mitochondrial lineages among the 20 haplotypes found in the Brazilian populations of $A n$. darlingi. Haplotypes from mosquitoes collected in different periods were distributed homogeneously on the tree.

\section{DISCUSSION}

The results showed high polymorphism in the sequenced region of the ND4 gene. Of the 218 mosquitoes analyzed, we obtained 20 different haplotypes with an index of diversity of 0.756 (mean of the two collections) and a nucleotide diversity of 0.0119 . Similar nucleotide diversity was obtained by Conn et al. (1999) with An. darlingi from Brazil, Bolivia, and Venezuela, in that case through the use of restriction enzymes. Other investigators have obtained similar indexes from other mitochondrial genes for other neotropical anophelines such as Anopheles rangeli and Anopheles trinkae from Bolivia and Ecuador (Conn et al. 1997), and Anopheles nuneztovari from Brazil (Conn et al. 1998). Like the Nearctic species Anopheles quadrimaculatus, An. darlingi shows characteristics of a panmictic species with little population structure on a continental scale (Perera et al. 1995). Mirabello and Conn (2006) studying An. darlingi showed that the inference of range expansion was well supported but isolation by distance was not. Isolation by distance and the low nucleotide diversity observed in Central America populations of Anopheles albimanus and low nucleotide diversity in An. darlingi could be due to small effective migration rates and effective population size, and/or genetic drift (Merida et al. 1999, Molina-Cruz el al. 2004).

The analyzed An. darlingi populations of Porto Velho did not showed population structuring. The same pattern of haploype distribution was observed by Molina-Cruz et al. (2004) in An. albimanus populations from Central America. Mitochondrial analysis could only differentiate populations from South America (Colombia and Venezuela) and Panama from those collected in Central America. Weak isolation by distance from these populations was only found with microsatellites (MolinaCruz et al. 2004). Also microsatellites detected isola-

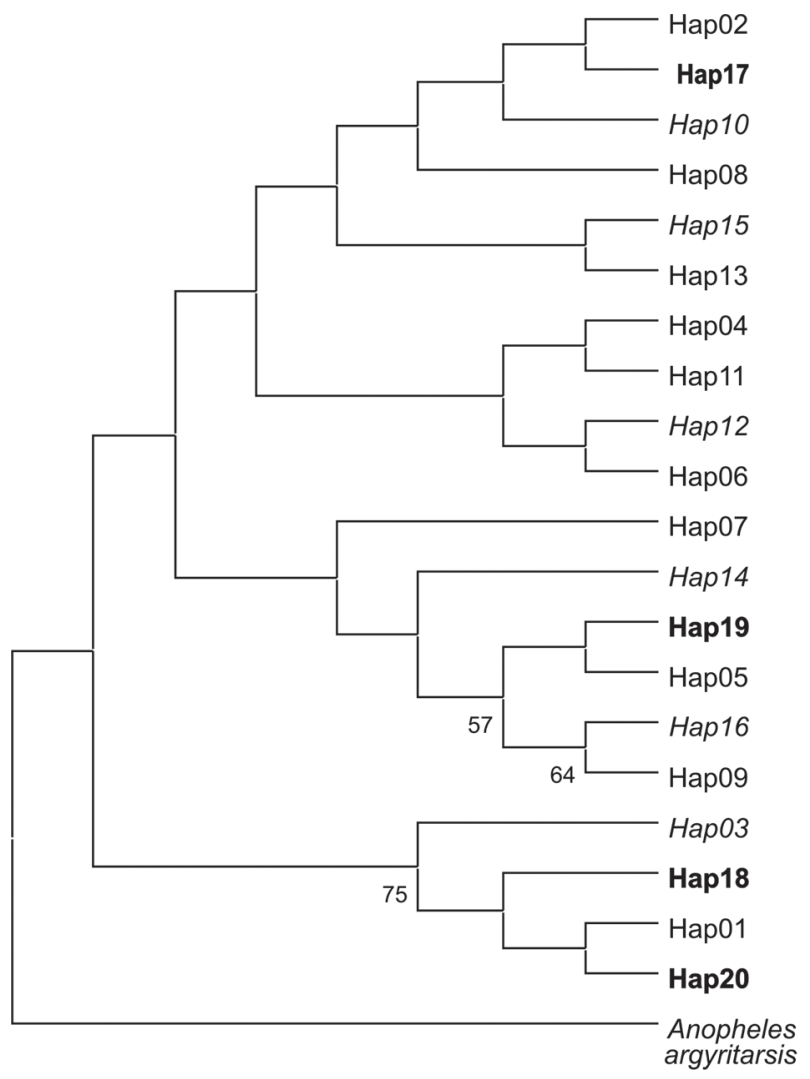

Fig. 4: maximum parsimony tree showing the phylogenetic relationships among Anopheles darlingi ND4 haplotypes found in Rondônia. Haplotypes in bold are exclusively from April, and those in italics are exclusively from October. The other haplotypes are common to the two periods. Numbers in the branches represent bootstrap values. The sequence of Anopheles argyritarsis was used as the outgroup.

tion by distance in An. darlingi from central and western Brazilian Amazon. In this study, Scarpassa and Conn (2007) showed that populations at distances $\leq 152 \mathrm{~km}$ presented high gene flow. Most of these studies were performed with mosquitoes collected over wide geographical ranges (continental range). Our local study in Rondônia found non significant differences in mosquitoes collected only $30 \mathrm{~km}$ apart, perhaps due to the occurrence of few highly representative haplotypes.

There were no significant seasonal differences, except in the population at PT, which differed significantly between April and October. This may be of great importance for malaria transmission, because of the possibility of introduction of new parasite lineages depending on the time of year. Despite the fact that half of the haplotypes were exclusive to one period of the year, the absence of a significant difference also could be due to the highly representative haplotypes. The differences observed resulted from the presence of rare haplotypes that were not representative of the main population.

These data demonstrate the importance of molecular studies for characterizing populations of An. darlingi. Such studies can support the traditional methods of con- 
trol, especially regarding insecticide use, because of potential mosquito population or species-level adaptation. Knowledge of mosquito population dynamics could also be used to monitor the introduction of new lineages that may have different transmission competence. It is also clear that there is a need for discriminatory molecular tools to resolve local subjects of distribution of the vectors, tools that must be multi-locus because of the high complexity of the system. This is important for epidemiology, because new strains of the mosquito may be more efficient vectors or even harbor different strains of Plasmodium.

\section{ACKNOWLEDGEMENTS}

To the field team of LHS Gil at CEPEM and IPEPATRO, for logistical support in collecting mosquito samples.

\section{REFERENCES}

Brown WM 1985. The mitochondrial genome of animals. In RJ Macintyre (ed.), Molecular evolutionary genetics. Plenum Press, New York, p. 95-130.

Chakraborty R, 1990. Mitochondrial DNA polymorphism reveals hidden heterogeneity within some Asian populations. Am J Hum Genet 47: 87-94.

Conn JE, Mitchell SE, Cockburn AF 1997. Mitochondrial DNA variation within and between two species of neotropical anopheline mosquitoes (Diptera: Culicidae). J Heredity 88: 98-107.

Conn JE, Mitchell SE, Cockburn AF 1998. Mitochondrial DNA analysis of the neotropical malaria vector Anopheles nuneztovari. Genome 41: 313-327.

Conn JE, Rosa-Freitas MG, Luz SL, Momen H 1999. Molecular population genetics of the primary neotropical malaria vector Anopheles darlingi using mtDNA. J Am Mosq Control Assoc 15: 468-474.

Consoli RAGB, Lourenço-de-Oliveira R 1994. Principais mosquitos de importância sanitária no Brasil, Fiocruz, Rio de Janeiro, 225 pp.

Deane LM 1947. Observações sobre a malária na Amazônia brasileira. Rev Serv Esp Saude Publ 1: 3-60.

Deane LM 1988. Malaria studies and control in Brazil. Am J Trop Med Hyg 38: 223-230.

Excoffier L, Laval G, Schneider S 2005. Arlequin ver. 3.0: An integrated software package for population genetics data analysis. Evol Bioinf Online 1: 47-50.

Felsenstein J 1985. Confidence limits on phylogenies: an approach using the bootstrap. Evolution 39: 783-791.

Forattini OP 2002. Culicidologia Médica: Identificação, Biologia, Epidemiologia, Vol. 2, Universidade de São Paulo, São Paulo, 864 pp.

Gil LH, Alves FP, Zieler H, Salcedo JM, Durlacher RR, Cunha RP, Tada MS, Camargo EP, Pereira da Silva LH 2003. Seasonal malaria transmission and variation of anopheline density in two distinct endemic areas in Brazilian Amazonia. $J$ Med Entomol 40: 636-641.

Gil LH, Tada MS, Katsuragawa TH, Ribolla PE, da Silva LH 2007. Urban and suburban malaria in Rondônia (Brazilian Western Amazon) II. Perennial transmissions with high anopheline densities are associated with human environmental changes. Mem Inst Oswaldo Cruz 102: 271-276.
Gorrochotegui-Escalante N, Munoz ML, Fernandez-Salas I, Beaty BJ, Black WC 2000. Genetic isolation by distance among Aedes aegypti populations along the northeastern coast of Mexico. Am J Trop Med Hyg 62: 200-209.

Harris AF, Matias-Arnez A, Hill N 2006. Biting time of Anopheles darlingi in the Bolivian Amazon and implications for control of malaria. Trans R Soc Trop Med Hyg 100: 45-47.

Harrison RG 1989. Animal mitochondrial DNA as a genetic marker in population and evolutionary biology. Trends Ecol Evol 4: 6-11.

Kimura M 1980. A simple method for estimating evolutionary rates of base substitutions through comparative studies of nucleotide sequences. J Mol Evol 16: 111-120.

Klein TA, Lima JBP, Tada MS 1991. Comparative susceptibility of anopheline mosquitoes to Plasmodium falciparum in Rondônia, Brasil. Am J Trop Med Hyg 44: 598-603.

Kumar S, Tamura K, IB Jakobsen, Nei M 2001. MEGA2: Molecular Evolutionary Genetics Analysis software. Bioinformatics 17: 1244-1245.

Merida AM de, Palmieri M, Yurrita M, Molina A, Molina E, Black WC 1999. Mitochondrial DNA variation among Anopheles albimanus populations. Am J Trop Med Hyg 61: 230-239.

Mirabelo L, Conn JE 2006. Molecular population genetics of the malaria vector Anopheles darlingi in Central and South America. Heredity 96: 311-321.

Molina-Cruz A, Mérida AM de, Mills K, Rodríguez F, Schoua C, Yurrita MM, Molina E, Palmieri M, Black WC 2004. Gene flow among Anopheles albimanus populations in Central America, South America, and the Caribbean assessed by microsatellites and mitochondrial DNA. Am J Trop Med Hyg 71:350-359.

Moritz C, Dowling TE, Brown WM 1987. Evolution of animal mitochondrial DNA: relevance for population biology and systematics. Annu Rev Ecol Syst 18: 269-292.

Perera OP, Mitchell SE, Cockburn AF, Seawright JA 1995. Variation in mitochondrial and ribosomal DNA of Anopheles quadrimaculatus species A (Diptera: Culicidae) across a wide geographic range. Ann Entomol Soc Am 88: 836-845.

Rozas J, Rozas R 1999. DnaSP version 3: an integrated program for molecular population genetics and molecular evolution analysis. Bioinformatics 15: 174-175.

Saitou N, Nei M 1987. The neighbor-joining method: a new method for reconstructing phylogenetic trees. Mol Biol Evol 4: 406-425.

Sambrook J, Fritsh EF, Maniats T 1989. Molecular Cloning: a laboratory manual, 2nd ed., Cold Spring Harbor Laboratory Press, NY, USA, 720 pp.

Scarpassa VM, Conn JE 2007 Population genetic structure of the major malaria vector Anopheles darlingi (Diptera: $\mathrm{Cu}-$ licidae) from the Brazilian Amazon, using microsatellite markers. Mem Inst Oswaldo Cruz 102: 319-327.

Tadei WP, Mascarenhas BM, Podestá MG 1983. Biologia de anofelinos amazônicos. VIII. Conhecimento sobre a distribuição de espécies de Anopheles na região de TucuruíMarabá (Pará). Acta Amaz 13: 103-140.

Tadei WP, Thatcher BD, Santos JM, Scarpassa VM, Rodrigues IB, Rafael MS 1998. Ecologic observations on anopheline vectors of malaria in the Brazilian Amazon. Am J Trop Med Hyg 59: 325-335. 
Thompson JD, Higgins DG, Gibson TJ 1994. CLUSTAL W: improving the sensitivity of progressive multiple sequence alignment through sequence weighting, position specific gap penalties and weight matrix choice. Nucleic Acids Res 22: 4673-4680.

Voorham J 2002. Intra-population plasticity of Anopheles darlingi' (Diptera, Culicidae) biting activity patterns in the state of Amapá, Brasil. Rev Saude Publica 36: 75-80.

Yamauchi MM, Miya MU, Nishida N 2004. Use of a PCR-based approach for sequencing whole mitochondrial genomes of insects: two examples (cockroach and dragonfly) based on the method developed for decapod crustaceans. Insect Mol Biol 13: 435-442. 